\title{
Associative recall in verbal-discrimination learning as related to pronunciation and degree of practice'
}

ROBERT J. SARDELLO AND DONALD H. KAUSLER

SAINT LOUIS UNIVERSITY

Modified free recall (MFR) of associations between intrapair wrong (W) and right ( $R$ ) items learned incidentally during practice on an intentional verbal-discrimination (VD) leaming task was related to direction of recall (W-R versus $\mathrm{R}-\mathrm{W})$, the presence-absence of overt pronunciation of $W$ and $R$ items during the informative feedback exposures of VD practice, and degree of practice (five versus 10 trials) on the VD task. MFR for both W-R and R-W associations increased with overt verbalization and with greater practice, but $W-R$ and $R-W$ recall did not differ in amount. Associative matching of intrapair W and $\mathrm{R}$ items also increased with overt verbalization and degree of practice. Pronunciation was found to be accompanied by a decrease in proficiency of learning the intentional VD task.

A recent study by Kausler \& Sardello (1967) presented evidence supporting the contention that a verbaldiscrimination (VD) learning task can be viewed as a Type 2 incidental learning situation (McLaughlin, 1965) in which incidental and intentional learning occur simultaneously. The incidental components measured were the learning of both wrong (W) and right (R) items as responses. Overt pronunciation, a procedure employed by Mechanic $(1962,1964)$ to increase incidental learning in other Type 2 tasks, resulted in an increase in free recall of both $W$ and $R$ items, with the effect being greater for the $W$ items than for the $\mathbf{R}$ items. It is likely that another incidental component of VD learning involves the learning of $W-R$ and $R-W$ intrapair associations. Evidence for small to moderate amounts of $\mathrm{VD}$ associative learning has been presented by Battig, Williams, \& Williams (1962), Spear, Ekstrand, \& Underwood (1964), and Keppel (1966) with either nonsense syllables or lowfrequency words as $W$ and $R$ items. However, a number of transfer studies (Dean, 1966; Kausler \& Dean, in press; Kausler, Fulkerson, \& Eschenbrenner, in press) have implied that the amount of VD associative learning is considerably larger when the $W$ and $R$ items are highly meaningful words.

The present study investigated the effects on VD intrapair associative learning of independent variables that have been previously demonstrated to affect the amount of incidental learning in VD-namely, type of item recalled ( $W$ versus $R$ ), the presence-absence of overt pronunciation of $W$ and $R$ items, and the degree of practice on the intentional VD recognition task (Kausler \& Sardello, 1967). The dependent variables were modified free recall of intrapair associ- ations and associative matching of intrapair $\mathrm{W}$ and $R$ items. The hypothesis was that the amount of Type 2 incidental learning of $W-R$ and $R-W$ associations increases with the extent of pronunciation required during VD practice, the number of trials on the intentional task, and the direction of recall $(W-R>$ than $R-W)$.

\section{Method}

The design for modified free recall was a 2 by 2 by 2 mixed factorial with two between-group variables and one within-group variable. The between-group variables were pronunciation(P)-nonpronunciation(NP) of $\mathbf{W}$ and $\mathbf{R}$ items during feedback exposures and trials (five versus 10 ) on the VD task; the within-group variable was the direction of recall ( $W-R$ versus $\mathrm{R}-\mathrm{W})$ required during modified free recall. For associative matching the design was a 2 by 2 between-group factorial with pronunciation and trials as the variables. Forty undergraduate Ss were alternately assigned to Groups 5P, 5NP, 10P, and 10NP.

The selection and assignment of words for the 15 pair VD list, as well as the method of presentation and the instructions for VD learning, followed exactly the procedure outlined in the previous study (Kausler \& Sardello, 1967). After the specified number of VD trials the Ss were given a modified free recall (MFR) task, without a time limit, by the usual procedure of listing stimulus items in a column with a blank space for the recalled item next to each stimulus. The order of MFR was counterbalanced such that half of the Ss in each group were asked to recall $W$ items in the presence of $R$ items first, followed by recall of $R$ items in the presence of $W$ items, and the other half had the sequence reversed. Following MFR Ss were asked to match $W$ and $R$ items when the items were presented on a page with $W$ items on the left and $R$ items on the right. Order of recall was unrelated to the dependent variables and was eliminated from the statistical analyses reported below.

\section{Results and Discussion}

Summary data for MFR and for associative matching are given in Table 1 for Groups 5P, 5NP, 10P, and 10NP. A mixed analysis of variance of the MFR data revealed significant main effects for pronunciation $(F=10.41, \mathrm{df}=1 / 36, \mathrm{p}<.01)$ and for trials $(F$ $=36.05, \mathrm{df}=1 / 36, \mathrm{p}<.001)$. The main effect for direction of recall did not approach significance $(F<1)$, and all interactions fell short of significance $(F s<2)$. The analysis of variance of the associative matching 
Table 1. Summary Statistics for Modified Free Recall (MFR) and Associative Matching of Wrong (W) and Right (R) Items

\begin{tabular}{lrrrrrr} 
& \multicolumn{2}{c}{$R-W$ recall } & \multicolumn{2}{c}{ W-R recall } & \multicolumn{2}{c}{ Matching } \\
Group & Mean & SD & Mean & SD & Mean & SD \\
\hline 5P & 7.91 & 2.53 & 8.00 & 2.88 & 11.20 & 2.45 \\
5NP & 6.70 & 3.30 & 7.20 & 3.15 & 8.01 & 2.64 \\
IOP & 13.01 & 2.10 & 12.20 & 2.52 & 13.92 & 1.67 \\
10NP & 9.73 & 2.89 & 9.60 & 3.16 & 12.30 & 2.45 \\
\hline
\end{tabular}

data revealed significant main effects for pronunciation $(F=7.18, d f=1 / 36, p<.02)$ and trials $(F=15.39$, $\mathrm{df}=1 / 36, p<.01)$, but the interaction was not significant $(F<1)$.

The significant main effect for trials in both analyses and the absence of a significant trials by direction of recall interaction in the MFR analysis indicate that incidental associative learning increased bidirectionally with degree of practice on the VD task, a finding in agreement with that of Mechanic (1962) for a different Type 2 situation and with Kausler \& Sardello (1967) for free recall of $W$ and $R$ items in a VD task. The significant main effect for pronunciation in both analyses and the absence of a pronunciation by direction of recall interaction in MFR analysis suggest that overt verbalization increases the associative connections between $W$ and $R$ items symmetrically. The nonsignificant effect for direction of recall in the MFR analysis indicates that $W-R$ and $R-W$ recall are perhaps equal and that $W-R$ and $R-W$ associative learning may be symmetrical. A frequency theory of VD learning as proposed by Ekstrand, Wallace, \& Underwood (1966) suggests that recall availability of $R$ items should be superior to that of $W$ items in that $R$ items are responded to more frequently than are $W$ items as VD learning progresses, as was found to be true with free recall of $W$ and $R$ items in the Kausler \& Sardello (1967) study. In MFR, however, the presence of the $W$ or $R$ item seemingly increases the availability of the response required of $S$ to the extent that the effect of prior differential frequency of responding is no longer apparent.

The effect of pronunciation on the intentional VD task was also determined. For this analysis, only the first five trials of Groups 10P and 10NP were considered, thus yielding two groups (Groups P and NP) with $N=20$. The mean number of errors over five trials and the related standard deviation were 21.80 and 5.20 for Group $P$ and 16.00 and 6.08 for Group NP, with the difference in means being significant $(t=2.10$, $d f=38, p<.05)$. Thus, overt verbalization of $W$ and $R$ items was accompanied by a decrement in rate of VD learning. This finding is in agreement with a frequency theory of VD learning in that increasing the frequency of responding to $W$ items is expected to make differential frequency of $W$ and and $R$ responses a less reliable discriminative cue.

\section{References}

Battig, W. F., Williams, J. M., \& Williams, J. G. Transfer from verbal-discrimination to paired-associate learning. J. exp. Psychol., 1962, 63, 258-268.

Dean, M. G. Verbal-discrimination transfer as a function of right and wrong unit interlist similarity. Unpublished doctoral dissertation, Saint Louis University, 1966.

Ekstrand, B. R., Wallace, W. P., \& Underwood, B. J. A frequency theory of verbal-discrimination learning. Psychol. Rev., 1966, $73,566-578$

Kausler, D. H., \& Dean, M. G. Direct and mediated transfer for right and wrong responses in verbal-discrimination learning. $J$. verbal Leam. verbal Behav., in press.

Kausler, D. H., Fulkerson, F. E., \& Eschenbrenner, A. J., Jr. Unlearning of List 1 right items in verbal-discrimination transfer. J. exp. Psychol., in press.

Kausler, D. H., \& Sardello, R. J. Item recall in verbal-discrimination learning as related to pronunciation and degree of practice. Psychon. Sci., 1967, 7, 285-286.

Keppel, G. Association by contiguity: Role of response availability. J. exp. Psychol., 1966, 71, 624-628.

Mechanic, A. The distribution of recalled items in simultaneous intentional and incidental learning. J. exp. Psychol., 1962, 63, 593-600.

Mechanic, A. The responses involved in the rote learning of verbal materials. J. verbal Learn. verbal Behav., 1964, 3, 30-36.

Spear, N. E., Ekstrand, B. R., \& Underwood, B. J. Association by contiguity. J. exp. Psychol., 1964, 67, 151-161.

\section{Note}

1. This study was supported in part by a NASA Pre-doctoral Fellowship awarded to the first author. 